\title{
Physical Activity Plays an Important Role in Body Weight Regulation
}

\author{
Jean-Philippe Chaput, ${ }^{1}$ Lars Klingenberg, ${ }^{1}$ Mads Rosenkilde, ${ }^{2}$ Jo-Anne Gilbert, ${ }^{3}$ \\ Angelo Tremblay, ${ }^{3}$ and Anders Sjödin ${ }^{1}$ \\ ${ }^{1}$ Department of Human Nutrition, Faculty of Life Sciences, University of Copenhagen, Rolighedsvej 30, \\ DK-1958 Frederiksberg C, Copenhagen, Denmark \\ ${ }^{2}$ Department of Biomedical Sciences, Center for Healthy Aging, University of Copenhagen, \\ DK-1958 Frederiksberg C, Copenhagen, Denmark \\ ${ }^{3}$ Division of Kinesiology, Department of Social and Preventive Medicine, Faculty of Medicine, \\ Laval University, QC, Canada G1K 7P4
}

Correspondence should be addressed to Jean-Philippe Chaput, jepc@life.ku.dk

Received 29 April 2010; Accepted 29 June 2010

Academic Editor: Robert J. Ross

Copyright (C) 2011 Jean-Philippe Chaput et al. This is an open access article distributed under the Creative Commons Attribution License, which permits unrestricted use, distribution, and reproduction in any medium, provided the original work is properly cited.

\begin{abstract}
Emerging literature highlights the need to incorporate physical activity into every strategy intended to prevent weight gain as well as to maintain weight loss over time. Furthermore, physical activity should be part of any plan to lose weight. The stimulus of exercise provides valuable metabolic adaptations that improve energy and macronutrient balance regulation. A tight coupling between energy intake and energy expenditure has been documented at high levels of physical exercise, suggesting that exercise may improve appetite control. The regular practice of physical activity has also been reported to reduce the risk of stress-induced weight gain. A more personalized approach is recommended when planning exercise programs in a clinical weight loss setting in order to limit the compensatory changes associated to exercise-induced weight loss. With modern environment promoting overeating and sedentary behavior, there is an urgent need for a concerted action including legislative measures to promote healthy active living in order to curb the current epidemic of chronic diseases.
\end{abstract}

\section{Introduction}

Regular, vigorous exercise has been necessary for survival throughout evolution. It is only during the past few decades that it has become possible for people to go through life with minimal physical activity. The modern way of living promotes comfort and well-being in a less energydemanding environment; however, we are not genetically adapted for this sedentary lifestyle. Physical inactivity has become so prevalent that it is common to refer to exercise as having "healthy benefits," even though the exercise-trained state is the biological normal condition $[1,2]$. It has long been known that regular physical activity induces multiple adaptations within skeletal muscles and the cardiorespiratory system, all of which providing positive outcomes for the prevention and treatment of many metabolic disorders $[3,4]$. Lack of exercise should rather be perceived as "abnormal" and associated with numerous health risks. The objective for us as researchers and health care practitioners is to be more innovative in finding ways to motivate people to exercise and adopt healthier lifestyle choices.

In the field of obesity research, physical exercise has been traditionally considered as a strategy to burn calories. However, physical exercise is much more than that. It is a stimulus that, when properly managed, contributes to a significant improvement in energy and macronutrient balance regulation and to global body functioning, that is, a precise regulation of body homeostasis [5]. It thus seems appropriate to propose that an active lifestyle can influence energy balance and body fat to a much greater extent than 


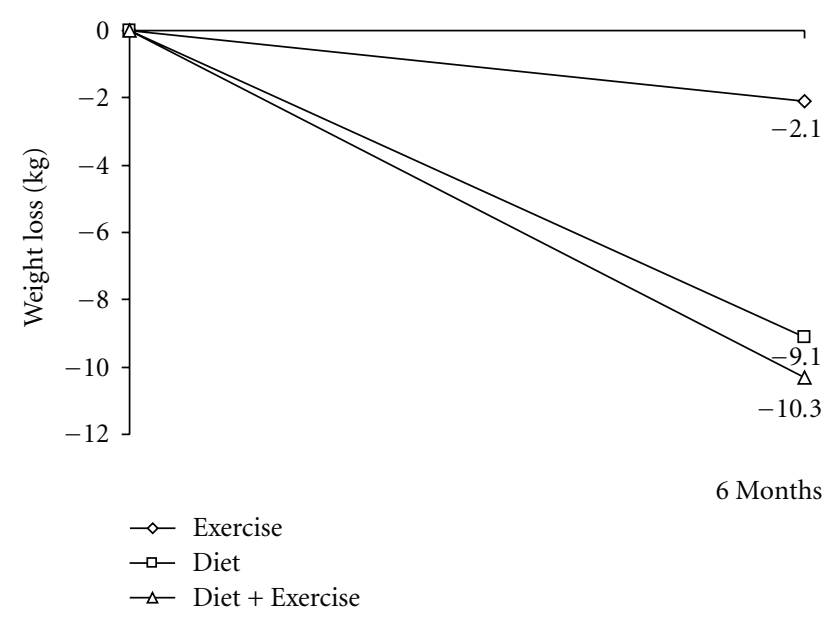

Figure 1: Weight loss related to an exercise intervention, a diet intervention, and a diet + exercise intervention. The magnitude of weight loss due to physical activity is additive to caloric restriction, but physical activity is generally insufficient by itself to bring about clinically significant weight loss, that is, a decrease of $5 \%$ or more in body weight. Figure adapted from Wing [6].

what is generally perceived by health professionals. To reach this outcome, exercise should ideally be performed regularly and on a permanent basis.

The main preoccupation of this conceptual paper is to discuss the critical role of physical activity in body weight regulation. The paper should not be perceived as an exhaustive literature review and critical analysis of the exercise-body weight connection, but rather an attempt to emphasize why and how physical exercise should be part of any plan to achieve body weight stability and overall health. Although the results of exercise programs designed to reduce body weight are generally considered disappointing [6] (see Figure 1), we still believe that exercise is an important player in obesity prevention and management. For the purpose of this paper, the general term "regular exercise" refers to the population-at-large consensus message that accumulation of 30 min of moderate intensity activity such as brisk walking, on at least 5 days of the week, can provide important health benefits.

\section{Physical Exercise: More Than a Calorie-Burning Agent}

There has been increasing evidence over the past decades of the importance of physical exercise in maintaining cardiovascular health and preventing diseases [7]. In recent years the list of beneficial effects has continued to grow. It has been shown that physically active individuals are less likely to develop stroke [8], some forms of cancer [9], type 2 diabetes [10], obesity [11], osteoporosis [12], sarcopenia [13], and loss of function and autonomy [14]. Evidence is also accumulating that exercise has profound benefits for brain function, including improvements in learning and memory as well as in preventing and delaying loss of cognitive function with aging or neurodegenerative disease
[15]. The knowledge gained from this large body of evidence is highlighting the crucial role of exercise to health and wellbeing, and it underscores the need to pay serious attention to this area of public health [7].

When sedentary individuals undertake exercise, the activity provides a massive stimulus with widespread physiological implications. The precise metabolic regulation brought about by exercise is expressed at many levels of regulatory processes, be it by stimulating the effect of key enzymes, by increasing cell sensitivity to numerous hormones, by facilitating substrate transport through membranes, by influencing cell receptors in a tissue-specific manner, and much more [5]. With the generalized sedentariness observed in modern societies, the human body needs to compensate for the lack of exercise stimulation to maintain energy and macronutrient balance. Fat gain and the metabolic syndrome are unfortunately the price to pay to maintain this balance [16].

The physiological perception of obesity considers fat gain as a biological adaptation that ultimately permits the person gaining weight to reach a new homeostatic state [17]. Some of the adaptations to this state of positive energy balance include an increase in fat oxidation [18], sympathetic nervous system activity [19], insulinemia at euglycemia [20], and leptinemia [21], all of which promoting over time the reequilibration of energy balance. However, fat gain cannot fully replace the positive impact conferred by a healthy lifestyle. The problem related to fat gain as a physiological compensation to sedentariness is that it cannot occur with the same metabolic efficiency as exercise. Specifically, fat gain relies more on increased concentration of substrates (e.g., free fatty acids) and hormones (e.g., insulin and leptin) to reequilibrate energy balance, which likely underlies the occurrence of the metabolic syndrome. These observations reinforce the relevance of adhering to healthy diet and physical activity habits in order to maintain body weight stability rather than relying on the overuse of regulatory systems soliciting the effects of hyperinsulinemia on the control of energy intake and expenditure.

In the context of weight management, it is more and more recognized that exercise should be encouraged and the emphasis on weight loss reduced [22-24]. This is concordant with the evidence that cardiorespiratory fitness is a more powerful predictor of cardiovascular and mortality risk than body weight $[25,26]$. The culture of focusing on body weight as the sole indicator of success is misleading because exercise without weight loss has been reported to be associated with marked reductions in abdominal fat and increases in skeletal muscle mass [27]. Moreover, body weight per se does not seem to be the most important risk factor for obesity comorbidities [28-30]. It is nevertheless understandable that many people feel disappointed by the poor weight loss success of exercise.

According to King et al. [31], the general perception that exercise is futile for weight management is damaging, and a more transparent and positive attitude to the health benefits of exercise is required. Therefore, there is a need to promote physical exercise and to prevent it being undervalued by the community and by public health professionals $[25,31]$. 


\section{Exercise-Induced Negative Energy Balance}

The ability of exercise to induce an overall body energy deficit or to prevent a positive energy balance within a given period of time depends on its energy cost, its ability to modify postexercise energy metabolism, and the postexercise compensation in energy intake [5]. Furthermore, the resulting exercise-related energy balance is influenced by exercise modalities (type, duration, frequency, and intensity) as well as the nutritional context surrounding its practice.

Beyond the energy cost of exercise, early studies have shown that an increase in energy metabolism can persist for many hours following the exposure to the exercise stimulus [32, 33]. Many years later, we confirmed this observation by demonstrating that resting metabolic rate was greater in endurance-trained individuals compared to the level predicted by their body weight [34]. Taken together, the energy cost of physical activity and its related increase in postexercise metabolic rate should normally induce a significant body weight loss if no compensation in energy intake occurs over time.

In the 1980s, Flatt [35] proposed the RQ:FQ concept according to which variations in energy balance correspond to those in macronutrient balance. In fact, since the regulation of carbohydrate and protein balance is precise, this concept ultimately implies that energy balance is equivalent to fat balance. Thus, the capacity of exercise to induce an energy deficit would depend on the ability to increase lipid oxidation above lipid intake. Importantly, this concept also emphasizes the impact of variations of body fat mass on fat oxidation. For instance, in the study of Schutz et al. [36], a change of $10 \mathrm{~kg}$ in fat mass was related to a change of $20 \mathrm{~g}$ in daily lipid oxidation in the same direction. If these results are applied to the context of a weight-reducing program, this would mean that 40 to $60 \mathrm{~min}$ of light to moderate exercise might be necessary to compensate for the decrease in fat oxidation resulting from a $10 \mathrm{~kg}$ fat mass loss. Our research experience with female elite swimmers agrees with this observation since a two-month interruption of regular intensive training resulted in a $4 \mathrm{~kg}$ fat gain corresponding to a positive energy balance of about $600 \mathrm{kcal} /$ day [37]. Thus, one of the main clinical implications of the RQ:FQ concept is that regular physical activity seems to be necessary to compensate for the weight loss-induced decrease in fat oxidation and thus prevent weight regain in a context where fat intake would be unchanged. This is consistent with data reported by Ewbank et al. [38] who found that exobese regular exercisers regained much less body weight compared to less active subjects.

The RQ:FQ concept also helps in understanding the effects of exercise modalities on body weight. As previously reviewed in [39], increasing exercise duration is related to some accentuation of weight loss and ultimately to the occurrence of a plateau. Once again, fat loss over time has a sufficient influence on weight regulation to compensate for the stimulating effects of exercise.

Our research has also been oriented towards the evaluation of exercise intensity per se on energy balance and body weight. In this case, the key question is whether, "calorie for calorie," an increase in exercise intensity is sufficient to modify the spontaneous coupling between energy intake and expenditure. The first answer to this question was provided by the Canada Fitness Survey which showed that after statistical adjustment for the energy cost of leisure time activities, subcutaneous adiposity was lower in individuals reporting the practice of vigorous physical activities [40]. Subsequently, the comparison of two exercise training programs revealed that for a given energy expenditure of exercise, subcutaneous fat loss was greater after a high intensity intermittent exercise program compared to a more conventional endurance training program [41]. This study also showed that high intensity exercise induced a more pronounced enhancing effect on the oxidative potential of skeletal muscle. Furthermore, experiments performed under standardized laboratory conditions confirmed the effects of exercise intensity, be it on postexercise spontaneous energy intake or energy expenditure/fat oxidation. Indeed, after having performed a $500 \mathrm{kcal}$-exercise of either low or high intensity, the postexercise compensation in ad libitum energy intake was lower when exercise intensity was high [42]. We repeated the same experimental strategy to measure the effect of vigorous exercise on postexercise energy metabolism. Specifically, high intensity exercise accentuated postexercise resting $\mathrm{VO}_{2}$ and fat oxidation which was, however, abolished by beta blockade [43]. This finding is relevant regarding the RQ:FQ concept [35], because it demonstrates the involvement of beta adrenergic stimulation as a mechanism underlying the stimulating effect of vigorous physical activity on fat oxidation.

In summary, the experience of many decades of investigation on the impact of physical activity on body weight shows that the exercise stimulus can influence energy balance. This effect is more pronounced when prolonged vigorous exercise is performed but clinical experience indicates that some individuals may be unable to take in charge such a physical demand. According to the RQ:FQ concept, one must also keep in mind that independently of the features of the exercise regimen, metabolic adaptations occurring with fat loss will progressively attenuate the anorexigenic and thermogenic effects of prolonged vigorous activity up to complete resistance to further lose fat. The obvious corollary of this observation is that exercise will thus have to be maintained in a reduced obese state to prevent further weight regain.

\section{Physical Exercise Improves the Accuracy by Which Energy Intake Is Matched with Energy Expenditure}

Several decades ago, Mayer et al. [44] evaluated the association between caloric intake, body weight, and physical work in an industrial male population in West Bengal (India). The mill workers covered a wide range of physical exercise, from sedentary to very hard work. The authors observed that caloric intake was greater in workers exposed to a greater labor demand, but only for moderate-to-high levels of physical exercise. In contrast, energy intake and 
energy expenditure were uncoupled in sedentary individuals. Indeed, energy intake was greater in sedentary workers compared to those performing light and medium work. These data are suggestive of a disruption in the accuracy by which energy intake is matched with energy expenditure at low levels of physical exercise and might explain, at least in part, why it is so difficult to prevent weight regain in sedentary individuals after a weight loss intervention. Conversely, a tight coupling between energy intake and energy expenditure has been documented at high levels of physical exercise $[45,46]$.

Furthermore, physical exercise has been shown to improve energy compensation in response to covert preload energy manipulation [47-49]. Indeed, active individuals seem more able to distinguish between preloads by adequately adjusting energy intake at a subsequent meal, denoting a better short-term appetite control. In contrary, sedentary individuals generally show a deficient homeostatic feedback control of hunger and satiety end are unable to distinguish between a low- and high-energy preload, and have similar energy intake at a subsequent meal [47-49]. The "long-term" effects of physical exercise on energy compensation in response to covertly manipulated preloads have also been recently investigated [50]. The authors observed an improved appetite control after a 6week moderate intensity exercise program in normal weight sedentary individuals, with a more sensitive eating behavior in response to previous energy intake. In addition, results from a recent randomized crossover study showed that acute exercise significantly increased postprandial levels of PYY, GLP-1, and pancreatic polypeptide in normal weight adults, suggesting that exercise can trigger physiological changes in hormone secretion, which could help in appetite control [51]. The transitory increase in the plasma levels of satiety hormones reported in the latter study may help to explain the short-term suppression of hunger observed after exercise, a phenomenon that is known as "exerciseinduced anorexia." Thus, it seems appropriate to say that exercisers display a better appetite control in general than their less active counterparts. However, short-term satiety data cannot directly be extrapolated to long-term appetite control, because adaptations may occur.

\section{Critical Role of Physical Activity in the Long-Term Weight Regulation}

The role of physical activity on the long-term prevention of weight gain or maintenance of weight loss has been assessed in numerous studies in the literature. Most recently, cross-sectional data from 7 European countries in the EPICPANACEA survey indexed a total of 125629 men and 280190 women into four categories according to self-reported physical activity practice and found that physical activity was inversely associated with BMI and waist circumference [52]. Prospective cohort studies investigating the relationship between obesity and levels of physical activity over time are fairly consistent. Most studies found that people who are physical active on a regular basis are less likely to gain weight [53-56]. Interestingly, Drøyvold et al. [56] found that subjects reporting exercise of higher intensities were less likely to gain weight than those reporting low intensity exercises, even after adjusting for baseline BMI and age. Furthermore, Kimm et al. [57] showed that a decline in physical activity in adolescence was related to increases in BMI and skin fold thickness over time. Given the risk of adolescence overweight and obesity for later development of obesity, these findings underscore the importance of physical activity in long-term weight regulation. In contrast, Petersen et al. [58] did not find a relationship between long-term physical activity participation and development of obesity. The study rather suggested that obesity may lead to physical inactivity.

The above-mentioned findings are important in establishing associations between long-term weight regulation and physical activity; however, randomized controlled trials are needed to investigate the causal relationship between these two factors. Few studies have been conducted in this area. Donnelly et al. [59] studied weight changes in response to a 16-month supervised exercise trial ( $45 \mathrm{~min} /$ day, 5 days/week) in overweight young men and women. They found that exercise produced $\sim 5 \mathrm{~kg}$ weight loss in male exercisers compared to controls. Whereas in women controls the weight gain was $\sim 3 \mathrm{~kg}$, the exercisers remained weight stable. Slentz et al. [60] studied the effects of different exercise volumes and intensities over 8 months on body weight and body fat distribution in middle-aged men and women with mild-to-moderate hypertension. Without a reduction in caloric intake, loss of both body mass and fat mass occurred in a dose-dependent manner in regards to exercise volume and intensity. Furthermore, the controls gained weight throughout the study period. In the Look AHEAD trial, a total of 5145 men and women with type 2 diabetes were studied [61]. Greater self-reported physical activity was the strongest correlate of weight reduction, followed by clinically significant endpoints such as treatment attendance and meal replacements.

In general, physical activity has not been regarded as the most effective strategy for obtaining weight loss. Several systematic reviews have showed that a lower weight loss can be expected by physical activity alone compared to caloric restriction [62-64]. However, many methodological issues, such as doses of physical activity, assessment of energy balance and energy intake, and variations in baseline variables (e.g., age, weight, and percentage of body fat) have to be considered when interpreting these findings. In recent years, several well-controlled studies that carefully matched energy deficits by either caloric restriction or physical activity have shown that weight loss through exercise can be achieved [65-67]. Furthermore, weight loss induced by exercise seems to reduce total and ectopic body fatness to a greater extent than caloric restriction [65-67], which is a finding of high clinical importance.

In more aggressive weight loss strategies, physical activity also plays an important role. Evans et al. [68] studied gastric bypass surgery patients at months 3, 6, and 12 postsurgery. Patients reporting participation in at least $150 \mathrm{~min} /$ week of moderate-to-high intensity exercise had greater weight loss at 6 and 12 months postsurgery. 
The US National Weight Control Registry, published in 2008 , reports that those who are successful at maintaining weight loss (individuals maintaining a $13.6 \mathrm{~kg}$ weight loss for more than 1 year) are an extremely physically active group, despite a large variance in individual levels of physical activity [69]. These findings have been confirmed by Jakicic et al. [70], who studied obese women randomly assigned to 1 of 4 groups based on physical activity energy expenditure (1000 versus $2000 \mathrm{kcal} /$ week) and intensity (moderate versus vigorous) with a concomitant decrease in daily dietary energy intake $(-1200$ to $-1500 \mathrm{kcal} /$ day $)$. Despite no difference in weight loss at 6 and 24 months between the groups, post hoc analyses showed that individuals sustaining a loss of $10 \%$ or more of initial body weight at 24 months reported performing more physical activity $(1835 \mathrm{kcal} /$ week or $275 \mathrm{~min} /$ week) compared to those sustaining a weight loss of less than $10 \%$ of initial body weight.

The reasons for this association between high levels of physical activity and successful maintenance of weight loss in the long term are not fully understood; however, it is probably related to the maintenance of resting metabolic rate or total daily energy expenditure. Redman et al. [71] randomized overweight subjects to either a low calorie diet $(\sim 900 \mathrm{kcal} /$ day), caloric restriction of $25 \%$ of daily energy requirements, or $12.5 \%$ caloric restriction plus $12.5 \%$ increase in energy expenditure by structured exercise. The authors observed that 6 months of caloric restriction resulted in a metabolic adaptation characterized by a reduction in free-living energy expenditure that is larger than what can be explained by changes in body weight and body composition. Furthermore, there was a reduction in free-living activity thermogenesis after caloric restriction which was prevented when caloric restriction was combined to exercise.

As mentioned previously, another explanation for the association between high levels of physical exercise and successful maintenance of weight loss in the long term pertains to the better coupling between energy intake and energy expenditure, thereby facilitating the maintenance of energy balance [46]. Finally, high levels of physical activity are associated with better adherence to energy-restricted diets [64]. All together, the emerging scientific literature highlights the need to incorporate physical activity into every strategy intended to prevent weight gain as well as to maintain weight loss over time.

\section{Contribution of Physical Exercise to Total Energy Expenditure}

Interindividual variation in total energy expenditure (TEE) is mainly a function of differences in body size and physical activity. The activity-induced energy expenditure (AIEE) as part of the TEE may contribute, under habitual conditions, to $5 \%$ in a very sedentary person [72] up to $75 \%$ in highly trained endurance athletes [73]. However, while total physical activity is positively correlated with TEE, the weight-reducing effect of intense physical activity often associated with structured exercise training/sport activities is less obvious [74]. Interventions comprising regular sessions of physical exercise of moderate or high intensity generally produced moderate weight loss, with considerable interindividual variability, that is less than what could be expected based on theoretical calculations of the energy cost of the exercise session per se [75]. The obvious explanation for this is that weight loss is generally accompanied by a coinciding upregulated motivation to eat, leading to compensatory increased energy intake. Another explanation is that total 24hour energy expenditure is not increased to the theoretically expected level in order to defend body mass. The latter explanation could be due to compensatory decreases in other daily activities, blunting the effect of exercise on TEE. A number of studies have, however, shown that the addition of moderate amounts of nonstrenuous physical activities, at least without dietary restriction, does not lead to a decrease in other activities for the remainder of the day [76-80].

The increase in TEE associated with physical exercise has actually been shown to be higher than the energy cost of the training program per se. Based on the results of four exercise intervention studies in nonelderly subjects [76-79], researchers found that the intervention-induced increase in TEE was in average $1.9 \mathrm{MJ} / \mathrm{d}$, and the calculated net energy cost of the training program was of $1.0 \mathrm{MJ} / \mathrm{d}$. These findings, combined with indications of maintained postexercise behavior, suggest that the cost of the exercise intervention was twice that could be expected from measurements or calculations of energy expenditure during the imposed exercise. Although no effects on basal metabolism were found in these studies when assessed $\geq 36 \mathrm{~h}$ after the last exercise session, it is still possible that the excess postexercise energy expenditure within this time frame partly explained these discrepancies [32, 33, 81], however, probably not to the full extent, leaving a part of this increase in TEE unexplained. Whatever the mechanisms behind these findings may be, the studies of Westerterp [82] as well as Goran and Poehlman [83] suggest that the difference between expected and measured increases in TEE is affected by the individual physical "burden" of the intervention. In the first study [82], the running distance was doubled (from 25 to $50 \mathrm{~km} /$ week) without any additional increase in TEE. In the second study [83], elderly subjects performed 3 intense cycling sessions weekly for 8 weeks but TEE did not increase $(-0.3 \mathrm{MJ} / \mathrm{d})$ although the energy cost of the training intervention per se was expected to be in average $0.6 \mathrm{MJ} / \mathrm{d}$.

We have previously reported that extremely fit endurance athletes of both sexes, expending in average $18.3 \mathrm{MJ} / \mathrm{d}$ (women) and $30.3 \mathrm{MJ} / \mathrm{d}$ (men) during periods of intense training, have approximately $15 \%$ higher basal metabolic rates than sedentary subjects matched for age, sex, and lean body mass, even $\geq 39 \mathrm{~h}$ postexercise $[73,84]$. Likewise, resistance training for 26 weeks in a previously unfit elderly population studied by Hunter et al. [85] resulted in marked increase in TEE $(965 \mathrm{~kJ} / \mathrm{d})$. This was, in addition to the energy expended during the training sessions $(215 \mathrm{~kJ} / \mathrm{d})$, attributed to increased resting metabolic rate $(365 \mathrm{~kJ} / \mathrm{d})$ as a result of increased lean body mass as well as to additional nontraining physical activities $(288 \mathrm{~kJ} / \mathrm{d})$.

A negative energy balance as a result of exercise combined with an imposed energy restriction may potentially modify 
the effect of exercise on TEE. Studies looking at the influence of exercise in combination with energy restriction have found marginal further effects on body weight following the addition of exercise [86]. Body weight seems to be defended during caloric restriction, involving at least 3 mechanisms: (i) a decrease in resting metabolic rate, although partly counteracted by exercise [87]; (ii) a reduction in nonexercise physical activity [71, 88] and as recently suggested; (iii) an increase in work efficiency. For instance, Goldsmith et al. [89] showed that the work efficiency (energy output divided by energy expended above resting energy expenditure) was increased by $15 \%$ when bicycling at 50 Watts after a $10 \%$ weight reduction. This is in line with the explanation offered by Westerterp et al. [79] for the lack of further increased TEE paralleling the increased exercise volume described above.

Finally, it should be noted that dietary induced thermogenesis (DIT) increases in direct proportion to the increased TEE if energy balance is maintained. In the case of welltrained endurance athletes, this could result in DIT four times higher than an average sedentary subject. It may account for up to almost $1000 \mathrm{kcal} / \mathrm{d}$ in extreme cases and should be considered when assessing the different components of TEE.

\section{Physical Exercise as a Buffer to the Deleterious Effects of Stress on Body Weight}

The role of chronic stress in the etiology of obesity is increasingly recognized [90-96]. In turn, the stress response of obese people has been shown to be exaggerated, which may further increase the risk of weight gain. Stress management has then been suggested as a weight control strategy to stop this vicious cycle [90] and, expectedly, lifestyle interventions targeting stress reduction have shown weight-control benefits [97]. Interestingly, the state of low physical activation appears to intensify the acute response to psychological stressors [92], and consistently sedentary lifestyles potentiate the stress-related health complications such as obesity, particularly visceral obesity [91, 95]. Thus, physical activity is suggested to decrease the risk of stressinduced obesity by (i) directly reducing the stress response and (ii) indirectly buffering the harmful effect of stress, as presented in Figure 2.

In the modern environment, where energy-dense foods are highly available and food cues very powerful, people tend to eat pleasurable foods to relieve stress [93]. However, the stress-induced feeding is not only the result of the behaviorfacilitating environment. When under threat, human body activates the hypothalamic-pituitary-adrenocortical (HPA) axis and the sympathetic nervous system (SNS) which leads to the release of glucocorticoids (cortisol) and catecholamines (adrenaline and noradrenaline), respectively [91, 92]. An increase in circulating cortisol is generally accompanied by hyperinsulinemia which may become chronic in the context of continuous stress [91, 92, 94]. The combined action of cortisol and insulin is known to increase the intake of pleasurable foods [94], and insulin blunts fatty acid

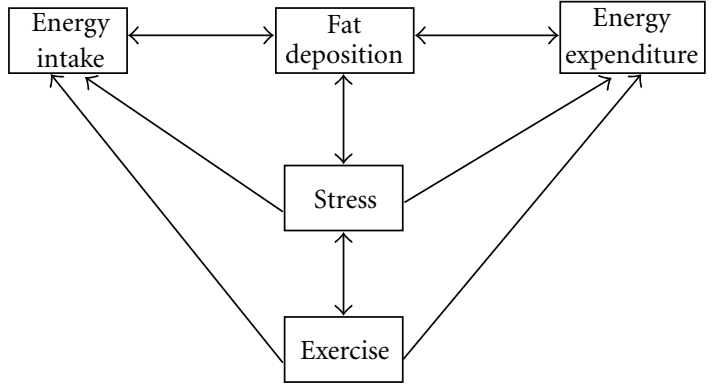

Figure 2: Potential influence of exercise on the interaction between stress and obesity.

oxidation which could lead to body fat gain. In addition, some evidence shows that hypercortisolemia leads to a state of leptin resistance and is also associated to an elevated neuropeptide Y release [91]. Both hormones (cortisol and neuropeptide $\mathrm{Y}$ ) are known to stimulate appetite [98]. In turn, eating hedonic foods appears to decrease the feeling of stress [94]. It affects the corticolimbic brain areas that regulate learning, memory, reward, mood, and emotions [93]. Therefore, the stress-induced feeding habit is reinforced every time something pleasurable is eaten to relieve psychological stress [94]. This vicious cycle must then be stopped by using another stress-reduction method [96] and, for its physiological and psychological effects, exercise practice seems a good option.

The neuroendocrine response to stress also influences fat deposition. In fact, the joint action of the HPA and SNS is to mobilize energy for the "fight or flight" response that has been for long time vital for humans [91]. In today's society, where stress is predominantly of psychosocial nature, the mobilized substrates are not used and rather stored. Since visceral adipose tissue is particularly sensitive to the combined signal of insulin and glucocorticoids, stress results in fat accumulation in the viscera [90-92, 94]. Moreover, stress-induced visceral fat deposition is further accentuated by the antithermogenic effect of cortisol [90] and the concomitant dysregulation in the thyroid axes and in the secretion of sex steroid and growth hormone [91].

In general, cross-sectional studies show a negative association between physical activity and stress levels, though such association is not significant in all of them [95]. Only few longitudinal and quasiexperimental studies have been conducted on the topic, but their results tend to support the cross-sectional evidence. For example, regular joggers showed a reduced risk of perceiving a high level of stress compared to sedentary individuals ( $\mathrm{OR}=0.33$ ) [99]. Moreover, experimental evidence in adolescents assigned to 10 weeks of high intensity aerobic training showed beneficial effects on perceived stress level in comparison to those who engaged in moderate aerobic or flexibility training or no exercise [100].

The main rationale for using exercise as a stress reduction strategy is mostly based on the cross-stressor adaptation hypothesis [101]. This theory suggests that a bout of exercise elicits a stress response which therefore leads to beneficial 
adaptations in the stress pathways that can transfer to psychosocial stressors. Although this hypothesis seemed promising in the 1990s, recent meta-analyses did not show a strong support [102-104]. Current research continues to investigate the possible mechanisms that may explain the stress-reducing effect of exercise.

The key question now is whether physical activity, which seems to modulate the level of stress, may interact in the relationship between stress and obesity. Research on such triadic relationship is at a very early stage. In fact, only one study verified specifically the three-way interaction. Yin et al. [96] showed that the interaction of stress and exercise predicted adiposity measures in adolescents. The authors of a recent review about the effect of exercise on stress and metabolic syndrome/obesity were also in favor of the beneficial effect of exercise on the relationship between stress and adiposity [92]. Different possible mechanisms suggesting that exercise training might protect against the stressinduced obesity have been proposed. Apart from its possible direct effect on the modulation of the stress response, exercise training improves insulin sensitivity, which might counteract the insulin resistance state produced by chronic hypercortisolemia [91]. The secretion of insulin could then be reduced which thereby may diminish its deleterious impact on energy intake. In addition, exercise training enhances oxidative capacity of skeletal muscle [91]. In the long run, this could prevent stress-induced fat deposition by routing the energy mobilized in response to stressor toward oxidation rather than storage. Regular exercise produces psychological improvements that may help buffering the harmful effects of stress. It has beneficial antidepressant and anxiolytic effect $[91,105]$ and, as shown in a recent metaanalysis, depression increases the risk to develop obesity [106]. Exercise training also improves sleep patterns [95, 105]. Considering that bad sleeping habits is itself a stressor [107] that has been associated with increased risk of obesity [108], physical activity can have a stress-buffer effect. There is also some evidence that exercise influences health-related behaviors, such as nutrition, and might help coping with life's stress, particularly among high-risk individuals [95]. Then, when practiced on a regular basis, physical activity could help breaking the stress-feeding habits.

\section{How Can We Deal with the Interindividual Variability in Exercise-Induced Weight Loss?}

When promoting exercise training for weight loss purposes, we inevitably have to deal with the question of interindividual variability in the response to exercise training. Why some people lose weight by exercising whereas others do not? And how can we deal with these differences in a clinical setting?

Interindividual differences in the response to exercise training have been reported in the literature [75, 109, 110]. Although methodological issues can be responsible for the variability (e.g., differences in subjects' baseline characteristics) in some cases, these apparent differences can also be attributed to either compensatory behavioral changes or physiological adaptations to training $[75,109]$. The behavioral changes can be both volitional and nonvolitional and include compensatory eating, reduced daily life nonexercise activities, or simply lack of compliance to the prescribed exercise program. The physiological adaptations, as mentioned earlier, may include a lower resting metabolic rate, altered substrate utilization, and improved exercise efficiency due to a better physiological functioning of both circulatory and peripheral mechanisms and structures.

It is widely accepted that, when facing energy deficit, the body reacts by upregulating energy conserving compensatory responses. Independently or in combination, these different compensatory responses (both behavioral and physiological) act as a counterbalance mechanism when exercising for the purpose of weight loss. The timing and magnitude of these mechanisms can be different. However, it is evident that the behavioral changes (volitional or nonvolitional) contribute more to the compensatory component than the physiological adaptations $[109,111]$. Furthermore, physiological adaptations to exercise training are not factors which can be eliminated and, thus, are not susceptible to any treatment or deliberate changes. Hence, this suggests that it is important to recognize that behavioral changes might be a strong limiting factor in terms of achieving a successful body weight regulation. It is therefore necessary to uncover the behavioral changes on an individual basis in order to address them. This not only advocates a more individual approach when planning exercise programs in a clinical weight loss setting, but more importantly the possibility to monitor the patients' eating and activity patterns and to give them support and guidance targeting behavioral aspects. This personalized approach must also include other behavioral factors that have been shown to impede the weight loss response, such as sleep deprivation, stress, depressive symptoms, and weight cycling.

As stated previously in this paper, exercise training should not be isolated as a means to maintain weight stability or lose weight but should be considered as a way to promote health, quality of life and fight off diseases. The beneficial effect of engaging in regular exercise training is independent of weight loss, and for that reason alone, exercise training should be an integrated part of any weight loss program.

\section{Conclusion}

The vast majority of scientific evidence supports a beneficial role of exercise on achieving body weight stability and overall health. The goal is to find ways to motivate people to exercise and adopt healthy lifestyles. In order to achieve this objective, we must be innovative and creative in finding ways to fight against the modern way of living that drives excess energy intake relative to expenditure. Future research will be needed to give a better insight into the many issues impacting physical activity levels of people, including the barriers to healthy active living. Furthermore, we need to pay particular attention to the disparities in physical activity practice, because children with disabilities and those from 
low socio-economic status backgrounds are at a disadvantage. With experts around the world sounding the alarm about the consequences of escalading rates of obesity, type 2 diabetes, and cardiovascular disease, a concerted action including legislative measures to promote healthy active living is more than warranted [112]. Specifically, government intervention needs to take the form of appropriate legal and fiscal measures designed to make healthy choices more affordable, accessible, and acceptable. By doing so, we expect that the population as a whole will be healthier.

\section{Acknowledgments}

J.-P. Chaput, L. Klingenberg, M. Rosenkilde, and A. M. Sjöden are partly funded by the University of Copenhagen and the Nordea Foundation (OPUS Center). J.-A. Gilbert is supported by a studentship from the Danone Institute of Canada. A. Tremblay is partly funded by the Canada Research Chair in Environment and Energy Balance. The authors declared no conflict of interests.

\section{References}

[1] J. A. Hawley and J. O. Holloszy, "Exercise: it's the real thing!"” Nutrition Reviews, vol. 67, no. 3, pp. 172-178, 2009.

[2] F. W. Booth and S. J. Lees, "Physically active subjects should be the control group," Medicine and Science in Sports and Exercise, vol. 38, no. 3, pp. 405-406, 2006.

[3] B. K. Pedersen, "The anti-inflammatory effect of exercise: its role in diabetes and cardiovascular disease control," Essays in Biochemistry, vol. 42, pp. 105-117, 2006.

[4] J. A. Hawley, "Exercise as a therapeutic intervention for the prevention and treatment of insulin resistance," Diabetes/Metabolism Research and Reviews, vol. 20, no. 5, pp. 383-393, 2004.

[5] A. Tremblay and F. Therrien, "Physical activity and body functionality: implications for obesity prevention and treatment," Canadian Journal of Physiology and Pharmacology, vol. 84, no. 2, pp. 149-156, 2006.

[6] R. R. Wing, "Physical activity in the treatment of the adulthood overweight and obesity: current evidence and research issues," Medicine and Science in Sports and Exercise, vol. 31, no. 11, pp. S547-S552, 1999.

[7] S. N. Blair and J. N. Morris, "Healthy hearts-and the universal benefits of being physically active: physical activity and health," Annals of Epidemiology, vol. 19, no. 4, pp. 253-256, 2009.

[8] F. W. Booth, S. E. Gordon, C. J. Carlson, and M. T. Hamilton, "Waging war on modern chronic diseases: primary prevention through exercise biology," Journal of Applied Physiology, vol. 88, no. 2, pp. 774-787, 2000.

[9] S. W. Farrell, G. M. Cortese, M. J. Lamonte, and S. N. Blair, "Cardiorespiratory fitness, different measures of adiposity, and cancer mortality in men," Obesity, vol. 15, no. 12, pp. 3140-3149, 2007.

[10] S. P. Helmrich, D. R. Ragland, R. W. Leung, and R. S. Paffenbarger Jr., "Physical activity and reduced occurrence of non-insulin-dependent diabetes mellitus," New England Journal of Medicine, vol. 325, no. 3, pp. 147-152, 1991.

[11] L. Di Pietro, J. Dziura, and S. N. Blair, "Estimated change in physical activity level (PAL) and prediction of 5-year weight change in men: the Aerobics Center Longitudinal Study," International Journal of Obesity, vol. 28, no. 12, pp. 15411547, 2004.

[12] G. A. Greendale, E. Barrett-Connor, S. Edelstein, S. Ingles, and R. Haile, "Lifetime leisure exercise and osteoporosis. The Rancho Bernardo Study," American Journal of Epidemiology, vol. 141, no. 10, pp. 951-959, 1995.

[13] I. Janssen, S. B. Heymsfield, and R. Ross, "Low relative skeletal muscle mass (sarcopenia) in older persons is associated with functional impairment and physical disability," Journal of the American Geriatrics Society, vol. 50, no. 5, pp. 889-896, 2002.

[14] G. F. Fletcher, G. Balady, S. N. Blair et al., "Statement on exercise: benefits and recommendations for physical activity programs for all Americans: a statement for health professionals by the committee on exercise and cardiac rehabilitation of the Council on Clinical Cardiology, American Heart Association," Circulation, vol. 94, no. 4, pp. 857-862, 1996.

[15] H. van Praag, "Exercise and the brain: something to chew on," Trends in Neurosciences, vol. 32, no. 5, pp. 283-290, 2009.

[16] A. Tremblay, N. Boulé, É. Doucet, and S. C. Woods, "Is the insulin resistance syndrome the price to be paid to achieve body weight stability?" International Journal of Obesity, vol. 29, no. 10, pp. 1295-1298, 2005.

[17] A. Tremblay and E. Doucet, "Obesity: a disease or a biological adaptation?” Obesity Reviews, vol. 1, no. 1, pp. 27-35, 2000.

[18] J. Galgani and E. Ravussin, "Energy metabolism, fuel selection and body weight regulation," International Journal of Obesity, vol. 32, supplement 7, pp. S109-S119, 2008.

[19] L. J. Aronne, R. Mackintosh, M. Rosenbaum, R. L. Leibel, and J. Hirsch, "Autonomic nervous system activity in weight gain and weight loss," American Journal of Physiology, vol. 269, no. 1, pp. R222-R225, 1995.

[20] A. Tremblay, A. Nadeau, J.-P. Despres, and C. Bouchard, "Hyperinsulinemia and regulation of energy balance," American Journal of Clinical Nutrition, vol. 61, no. 4, pp. 827-830, 1995.

[21] R. V. Considine, M. K. Sinha, M. L. Heiman et al., "Serum immunoreactive-leptin concentrations in normalweight and obese humans," New England Journal of Medicine, vol. 334, no. 5, pp. 292-295, 1996.

[22] R. Ross and A. J. Bradshaw, "The future of obesity reduction: beyond weight loss," Nature Reviews Endocrinology, vol. 5, no. 6, pp. 319-326, 2009.

[23] P. M. Janiszewski and R. Ross, "Physical activity in the treatment of obesity: beyond body weight reduction," Applied Physiology, Nutrition and Metabolism, vol. 32, no. 3, pp. 512522, 2007.

[24] S. N. Blair and M. J. LaMonte, "Commentary: current perspectives on obesity and health: black and white, or shades of grey?" International Journal of Epidemiology, vol. 35, no. 1, pp. 69-72, 2005.

[25] S. N. Blair, "Physical inactivity: the biggest public health problem of the 21st century," British Journal of Sports Medicine, vol. 43, no. 1, pp. 1-2, 2009.

[26] S. N. Blair, H. W. Kohl III, C. E. Barlow, R. S. Paffenbarger Jr., L. W. Gibbons, and C. A. Macera, "Changes in physical fitness and all-cause mortality: a prospective study of healthy and unhealthy men," Journal of the American Medical Association, vol. 273, no. 14, pp. 1093-1098, 1995.

[27] R. Ross and P. M. Janiszewski, "Is weight loss the optimal target for obesity-related cardiovascular disease risk reduction?" Canadian Journal of Cardiology, vol. 24, pp. 25D-31D, 2008. 
[28] I. Janssen, P. T. Katzmarzyk, and R. Ross, "Waist circumference and not body mass index explains obesity-related health risk," American Journal of Clinical Nutrition, vol. 79, no. 3, pp. 379-384, 2004.

[29] P. Poirier, I. Lemieux, P. Mauriège et al., "Impact of waist circumference on the relationship between blood pressure and insulin: the Quebec Health Survey," Hypertension, vol. 45, no. 3, pp. 363-367, 2005.

[30] P. M. Janiszewski, I. Janssen, and R. Ross, "Does waist circumference predict diabetes and cardiovascular disease beyond commonly evaluated cardiometabolic risk factors?" Diabetes Care, vol. 30, no. 12, pp. 3105-3109, 2007.

[31] N. A. King, M. Hopkins, P. Caudwell, R. J. Stubbs, and J. E. Blundell, "Beneficial effects of exercise: shifting the focus from body weight to other markers of health," British Journal of Sports Medicine, vol. 43, no. 12, pp. 924-927, 2009.

[32] H. T. Edwards, A. Thorndike Jr., and D. B. Dill, "The energy requirement in strenuous muscular exercise," New England Journal of Medicine, vol. 213, pp. 532-535, 1935.

[33] R. Margaria, H. T. Edwards, and D. B. Dill, "The possible mechanisms of contracting and paying the $\mathrm{O} 2$ debt and the role of lactic acid in muscular contraction," American Journal of Physiology, vol. 106, pp. 689-715, 1933.

[34] A. Tremblay, E. Fontaine, E. T. Poehlman, D. Mitchell, L. Perron, and C. Bouchard, "The effect of exercise-training on resting metabolic rate in lean and moderately obese individuals," International Journal of Obesity, vol. 10, no. 6, pp. 511-517, 1986.

[35] J. P. Flatt, "Dietary fat, carbohydrate balance, and weight maintenance: effects of exercise," American Journal of Clinical Nutrition, vol. 45, no. 1, pp. 296-306, 1987.

[36] Y. Schutz, A. Tremblay, R. L. Weinsier, and K. M. Nelson, "Role of fat oxidation in the long-term stabilization of body weight in obese women," American Journal of Clinical Nutrition, vol. 55, no. 3, pp. 670-674, 1992.

[37] N. Alméras, S. Lemieux, C. Bouchard, and A. Tremblay, "Fat gain in female swimmers," Physiology and Behavior, vol. 61, no. 6, pp. 811-817, 1997.

[38] P. P. Ewbank, L. L. Darga, and C. P. Lucas, "Physical activity as a predictor of weight maintenance in previously obese subjects," Obesity Research, vol. 3, no. 3, pp. 257-263, 1995.

[39] A. Tremblay, J.-P. Després, and C. Bouchard, "The effects of exercise-training on energy balance and adipose tissue morphology and metabolism," Sports Medicine, vol. 2, no. 3, pp. 223-233, 1985.

[40] A. Tremblay, J.-P. Després, C. Leblanc et al., "Effect of intensity of physical activity on body fatness and fat distribution," American Journal of Clinical Nutrition, vol. 51, no. 2, pp. 153157, 1990.

[41] A. Tremblay, J.-A. Simoneau, and C. Bouchard, "Impact of exercise intensity on body fatness and skeletal muscle metabolism," Metabolism, vol. 43, no. 7, pp. 814-818, 1994.

[42] P. Imbeault, S. Saint-Pierre, N. Alméras, and A. Tremblay, "Acute effects of exercise on energy intake and feeding behaviour," British Journal of Nutrition, vol. 77, no. 4, pp. 511-521, 1997.

[43] M. Yoshioka, E. Doucet, S. St-Pierre et al., "Impact of highintensity exercise on energy expenditure, lipid oxidation and body fatness," International Journal of Obesity, vol. 25, no. 3, pp. 332-339, 2001.

[44] J. Mayer, P. Roy, and K. P. Mitra, "Relation between caloric intake, body weight, and physical work: studies in an industrial male population in West Bengal," American Journal of Clinical Nutrition, vol. 4, no. 2, pp. 169-175, 1956.
[45] N. A. King, A. Tremblay, and J. E. Blundell, "Effects of exercise on appetite control: implications for energy balance," Medicine and Science in Sports and Exercise, vol. 29, no. 8, pp. 1076-1089, 1997.

[46] C. Martins, L. Morgan, and H. Truby, "A review of the effects of exercise on appetite regulation: an obesity perspective," International Journal of Obesity, vol. 32, no. 9, pp. 1337-1347, 2008.

[47] N. A. King, K. Appleton, P. J. Rogers, and J. E. Blundell, "Effects of sweetness and energy in drinks on food intake following exercise," Physiology and Behavior, vol. 66, no. 2, pp. 375-379, 1999.

[48] S. J. Long, K. Hart, and L. M. Morgan, "The ability of habitual exercise to influence appetite and food intake in response to high- and low-energy preloads in man," British Journal of Nutrition, vol. 87, no. 5, pp. 517-523, 2002.

[49] E. L. van Walleghen, J. S. Orr, C. L. Gentile, K. P. Davy, and B. M. Davy, "Habitual physical activity differentially affects acute and short-term energy intake regulation in young and older adults," International Journal of Obesity, vol. 31, no. 8, pp. 1277-1285, 2007.

[50] C. Martins, H. Truby, and L. M. Morgan, "Short-term appetite control in response to a 6-week exercise programme in sedentary volunteers," British Journal of Nutrition, vol. 98, no. 4, pp. 834-842, 2007.

[51] C. Martins, L. M. Morgan, S. R. Bloom, and M. D. Robertson, "Effects of exercise on gut peptides, energy intake and appetite," Journal of Endocrinology, vol. 193, no. 2, pp. 251258, 2007.

[52] H. Besson, U. Ekelund, J. Luan et al., "A cross-sectional analysis of physical activity and obesity indicators in European participants of the EPIC-PANACEA study," International Journal of Obesity, vol. 33, pp. 497-509, 2009.

[53] N. Haapanen, S. Miilunpalo, M. Pasanen, P. Oja, and I. Vouri, "Association between leisure time physical activity and 10-yr body mass change among working-aged men and women," International Journal of Obesity and Related Metabolic Disorders, vol. 21, pp. 288-296, 1997.

[54] K. H. Schmitz, D. R. Jacobs Jr., A. S. Leon, P. J. Schreiner, and B. Sternfeld, "Physical activity and body weight: associations over ten years in the CARDIA study. Coronary Artery Risk Development in Young Adults," International Journal of Obesity and Related Metabolic Disorders, vol. 24, no. 11, pp. 1475-1487, 2000.

[55] D. F. Williamson, J. Madans, R. F. Anda, J. C. Kleinman, H. S. Kahn, and T. Byers, "Recreational physical activity and tenyear weight change in a US national cohort," International Journal of Obesity and Related Metabolic Disorders, vol. 17, no. 5, pp. 279-286, 1993.

[56] W. B. Drøyvold, J. Holmen, K. Midthjell, S. Lydersen, and The Nord-Trøndelag Health Study (HUNT), "BMI change and leisure time physical activity (LTPA): an 11-y follow-up study in apparently healthy men aged 20-69 y with normal weight at baseline," International Journal of Obesity, vol. 28, no. 3, pp. 410-417, 2004.

[57] S. Y. S. Kimm, N. W. Glynn, E. Obarzanek et al., "Relation between the changes in physical activity and body-mass index during adolescence: a multicentre longitudinal study," Lancet, vol. 366, no. 9482, pp. 301-307, 2005.

[58] L. Petersen, P. Schnohr, and T. I. A. Sørensen, "Longitudinal study of the long-term relation between physical activity and obesity in adults," International Journal of Obesity, vol. 28, no. 1, pp. 105-112, 2004. 
[59] J. E. Donnelly, J. O. Hill, D. J. Jacobsen et al., "Effects of a 16month randomized controlled exercise trial on body weight and composition in young, overweight men and women," Archives of Internal Medicine, vol. 163, no. 11, pp. 1343-1350, 2003.

[60] C. A. Slentz, B. D. Duscha, J. L. Johnson et al., "Effects of the amount of exercise on body weight, body composition, and measures of central obesity: STRRIDE-a randomized controlled study," Archives of Internal Medicine, vol. 164, no. 1, pp. 31-39, 2004.

[61] T. A. Wadden, D. S. West, R. H. Neiberg et al., "One-year weight losses in the look AHEAD study: factors associated with success," Obesity, vol. 17, no. 4, pp. 713-722, 2009.

[62] W. C. Miller, D. M. Koceja, and E. J. Hamilton, "A metaanalysis of the past 25 years of weight loss research using diet, exercise or diet plus exercise intervention," International Journal of Obesity, vol. 21, no. 10, pp. 941-947, 1997.

[63] M. Fogelholm and K. Kukkonen-Harjula, "Does physical activity prevent weight gain-a systematic review," Obesity Reviews, vol. 1, no. 2, pp. 95-111, 2000.

[64] V. A. Catenacci and H. R. Wyatt, "The role of physical activity in producing and maintaining weight loss," Nature Clinical Practice Endocrinology and Metabolism, vol. 3, no. 7, pp. 518529, 2007.

[65] R. Ross, D. Dagnone, P. J. H. Jones et al., "Reduction in obesity and related comorbid conditions after diet-induced weight loss or exercise-induced weight loss in men: a randomized, controlled trial," Annals of Internal Medicine, vol. 133, no. 2, pp. 92-103, 2000.

[66] R. Ross, I. Janssen, J. Dawson et al., "Exercise-induced reduction in obesity and insulin resistance in women: a randomized controlled trial," Obesity Research, vol. 12, no. 5, pp. 789-798, 2004.

[67] R. H. Coker, R. H. Williams, S. E. Yeo et al., "The impact of exercise training compared to caloric restriction on hepatic and peripheral insulin resistance in obesity," Journal of Clinical Endocrinology and Metabolism, vol. 94, no. 11, pp. 4258-4266, 2009.

[68] R. K. Evans, D. S. Bond, L. G. Wolfe et al., "Participation in $150 \mathrm{~min} /$ wk of moderate or higher intensity physical activity yields greater weight loss after gastric bypass surgery," Surgery for Obesity and Related Diseases, vol. 3, no. 5, pp. 526-530, 2007.

[69] V. A. Catenacci, L. G. Ogden, J. Stuht et al., "Physical activity patterns in the national weight control registry," Obesity, vol. 16, no. 1, pp. 153-161, 2008.

[70] J. M. Jakicic, B. H. Marcus, W. Lang, and C. Janney, "Effect of exercise on 24-month weight loss maintenance in overweight women," Archives of Internal Medicine, vol. 168, no. 14, pp. 1550-1559, 2008 .

[71] L. M. Redman, L. K. Heilbronn, C. K. Martin et al., "Metabolic and behavioral compensations in response to caloric restriction: implications for the maintenance of weight loss," PLoS ONE, vol. 4, no. 2, article e4377, 2009.

[72] K. R. Westerterp, "Physical activity as determinant of daily energy expenditure," Physiology and Behavior, vol. 93, no. 45, pp. 1039-1043, 2008.

[73] A. M. Sjödin, A. B. Andersson, J. M. Hogberg, and K. R. Westerterp, "Energy balance in cross-country skiers: a study using doubly labeled water," Medicine and Science in Sports and Exercise, vol. 26, no. 6, pp. 720-724, 1994.

[74] K. R. Westerterp and G. Plasqui, "Physical activity and human energy expenditure," Current Opinion in Clinical Nutrition and Metabolic Care, vol. 7, no. 6, pp. 607-613, 2004.
[75] N. A. King, P. Caudwell, M. Hopkins et al., "Metabolic and behavioral compensatory responses to exercise interventions: barriers to weight loss," Obesity, vol. 15, no. 6, pp. 1373-1383, 2007.

[76] S. A. Bingham, G. R. Goldberg, W. A. Coward, A. M. Prentice, and J. H. Cummings, "The effect of exercise and improved physical fitness on basal metabolic rate," British Journal of Nutrition, vol. 61, no. 2, pp. 155-173, 1989.

[77] E. E. Blaak, K. R. Westerterp, O. Bar-Or, L. J. M. Wouters, and W. H. M. Saris, "Total energy expenditure and spontaneous activity in relation to training in obese boys," American Journal of Clinical Nutrition, vol. 55, no. 4, pp. 777-782, 1992.

[78] L. M. L. A. Van Etten, K. R. Westerterp, F. T. J. Verstappen, B. J. B. Boon, and W. H. M. Saris, "Effect of an 18-wk weight-training program on energy expenditure and physical activity," Journal of Applied Physiology, vol. 82, no. 1, pp. 298304, 1997.

[79] K. R. Westerterp, G. A. L. Meijer, E. M. E. Janssen, W. H. M. Saris, and F. T. Hoor, "Long-term effect of physical activity on energy balance and body composition," British Journal of Nutrition, vol. 68, no. 1, pp. 21-30, 1992.

[80] R. P. Hollowell, L. H. Willis, C. A. Slentz, J. D. Topping, M. Bhakpar, and W. E. Kraus, "Effects of exercise training amount on physical activity energy expenditure," Medicine and Science in Sports and Exercise, vol. 41, no. 8, pp. 16401644, 2009.

[81] R. Bahr and S. Maehlum, "Excess post-exercise oxygen consumption. A short review," Acta Physiologica Scandinavica, vol. 128, supplement 556, pp. 99-104, 1986.

[82] K. R. Westerterp, "Alterations in energy balance with exercise," American Journal of Clinical Nutrition, vol. 68, no. 4, pp. 970S-974S, 1998.

[83] M. I. Goran and E. T. Poehlman, "Endurance training does not enhance total energy expenditure in healthy elderly persons," American Journal of Physiology, vol. 263, no. 5, pp. E950-E957, 1992.

[84] A. M. Sjödin, A. H. Forslund, K. R. Westerterp, A. B. Andersson, J. M. Forslund, and L. M. Hambræus, "The influence of physical activity on BMR," Medicine and Science in Sports and Exercise, vol. 28, no. 1, pp. 486-494, 1996.

[85] G. R. Hunter, C. J. Wetzstein, D. A. Fields, A. Brown, and M. M. Bamman, "Resistance training increases total energy expenditure and free-living physical activity in older adults," Journal of Applied Physiology, vol. 89, no. 3, pp. 977-984, 2000.

[86] J. S. Garrow and C. D. Summerbell, "Meta-analysis: effect of exercise, with or without dieting, on the body composition of overweight subjects," European Journal of Clinical Nutrition, vol. 49, no. 1, pp. 1-10, 1995.

[87] D. L. Ballor and E. T. Poehlman, "A meta-analysis of the effects of exercise and/or dietary restriction on resting metabolic rate," European Journal of Applied Physiology and Occupational Physiology, vol. 71, no. 6, pp. 535-542, 1995.

[88] C. K. Martin, L. K. Heilbronn, L. de Jonge et al., "Effect of calorie restriction on resting metabolic rate and spontaneous physical activity," Obesity, vol. 15, no. 12, pp. 2964-2973, 2007.

[89] R. Goldsmith, D. R. Joanisse, D. Gallagher et al., "Effects of experimental weight perturbation on skeletal muscle work efficiency, fuel utilization, and biochemistry in human subjects," American Journal of Physiology-Regulatory Integrative and Comparative Physiology, vol. 298, no. 1, pp. R79-R88, 2010. 
[90] V. Drapeau, F. Therrien, D. Richard, and A. Tremblay, "Is visceral obesity a physiological adaptation to stress?" Panminerva Medica, vol. 45, no. 3, pp. 189-195, 2003.

[91] A. Tsatsoulis and S. Fountoulakis, "The protective role of exercise on stress system dysregulation and comorbidities," Annals of the New York Academy of Sciences, vol. 1083, pp. 196-213, 2006.

[92] M. E. Holmes, P. Ekkekakis, and J. C. Eisenmann, "The physical activity, stress and metabolic syndrome triangle: a guide to unfamiliar territory for the obesity researcher," Obesity Reviews, vol. 11, no. 7, pp. 492-507, 2010.

[93] H. Zheng, N. R. Lenard, A. C. Shin, and H.-R. Berthoud, "Appetite control and energy balance regulation in the modern world: reward-driven brain overrides repletion signals," International Journal of Obesity, vol. 33, no. 2, pp. S8-S13, 2009.

[94] M. F. Dallman, "Stress-induced obesity and the emotional nervous system," Trends in Endocrinology and Metabolism, vol. 21, no. 3, pp. 159-165, 2010.

[95] M. Gerber and U. Pühse, "Do exercise and fitness protect against stress-induced health complaints? A review of the literature," Scandinavian Journal of Public Health, vol. 37, no. 8, pp. 801-819, 2009.

[96] Z. Yin, C. L. Davis, J. B. Moore, and F. A. Treiber, "Physical activity buffers the effects of chronic stress on adiposity in youth," Annals of Behavioral Medicine, vol. 29, no. 1, pp. 29$36,2005$.

[97] J. C. Rutledge, D. A. Hyson, D. Garduno, D. A. Cort, L. Paumer, and C. T. Kappagoda, "Lifestyle modification program in management of patients with coronary artery disease: the clinical experience in a tertiary care hospital," Journal of Cardiopulmonary Rehabilitation, vol. 19, no. 4, pp. 226-234, 1999.

[98] J. Cameron and E. Doucet, "Getting to the bottom of feeding behaviour: who's on top?" Applied Physiology, Nutrition and Metabolism, vol. 32, no. 2, pp. 177-189, 2007.

[99] P. Schnohr, T. S. Kristensen, E. Prescott, and H. Scharling, "Stress and life dissatisfaction are inversely associated with jogging and other types of physical activity in leisure timethe Copenhagen City Heart Study," Scandinavian Journal of Medicine and Science in Sports, vol. 15, no. 2, pp. 107-112, 2005.

[100] R. Norris, D. Carroll, and R. Cochrane, "The effects of physical activity and exercise training on psychological stress and well-being in an adolescent population," Journal of Psychosomatic Research, vol. 36, no. 1, pp. 55-65, 1992.

[101] M. S. Sothmann, J. Buckworth, R. P. Claytor, R. H. Cox, J. E. White-Welkley, and R. K. Dishman, "Exercise training and the cross-stressor adaptation hypothesis," Exercise and Sport Sciences Reviews, vol. 24, pp. 267-287, 1996.

[102] E. M. Jackson and R. K. Dishman, "Cardiorespiratory fitness and laboratory stress: a meta-regression analysis," Psychophysiology, vol. 43, no. 1, pp. 57-72, 2006.

[103] K. Forcier, L. R. Stroud, G. D. Papandonatos et al., "Links between physical fitness and cardiovascular reactivity and recovery to psychological stressors: a meta-analysis," Health Psychology, vol. 25, no. 6, pp. 723-739, 2006.

[104] M. Hamer, A. Taylor, and A. Steptoe, "The effect of acute aerobic exercise on stress related blood pressure responses: a systematic review and meta-analysis," Biological Psychology, vol. 71, no. 2, pp. 183-190, 2006.

[105] S. Brand, M. Gerber, J. Beck, M. Hatzinger, U. Pühse, and E. Holsboer-Trachsler, "High exercise levels are related to favorable sleep patterns and psychological functioning in adolescents: a comparison of athletes and controls," Journal of Adolescent Health, vol. 46, no. 2, pp. 133-141, 2010.

[106] F. S. Luppino, L. M. de Wit, P. F. Bouvy et al., "Overweight, obesity, and depression: a systematic review and meta-analysis of longitudinal studies," Archives of General Psychiatry, vol. 67, no. 3, pp. 220-229, 2010.

[107] R. Leproult and E. van Cauter, "Role of sleep and sleep loss in hormonal release and metabolism," Endocrine Development, vol. 17, pp. 11-21, 2010.

[108] J.-P. Chaput, J.-P. Després, C. Bouchard, and A. Tremblay, "The association between sleep duration and weight gain in adults: a 6-year prospective study from the Quebec Family Study," Sleep, vol. 31, no. 4, pp. 517-523, 2008.

[109] N. D. Barwell, D. Malkova, M. Leggate, and J. M. R. Gill, "Individual responsiveness to exercise-induced fat loss is associated with change in resting substrate utilization," Metabolism, vol. 58, no. 9, pp. 1320-1328, 2009.

[110] K. A. Snyder, J. E. Donnelly, D. J. Jabobsen, G. Hertner, and J. M. Jakicic, "The effects of long-term, moderate intensity, intermittent exercise on aerobic capacity, body composition, blood lipids, insulin and glucose in overweight females," International Journal of Obesity, vol. 21, no. 12, pp. 11801189, 1997.

[111] E. E. Blaak and W. H. M. Saris, "Substrate oxidation, obesity and exercise training," Best Practice and Research: Clinical Endocrinology and Metabolism, vol. 16, no. 4, pp. 667-678, 2002.

[112] N. M. Ries and B. von Tigerstrom, "Roadblocks to laws for healthy eating and activity," Canadian Medical Association Journal, vol. 182, no. 7, pp. 687-692, 2010. 


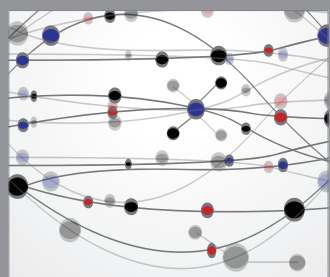

The Scientific World Journal
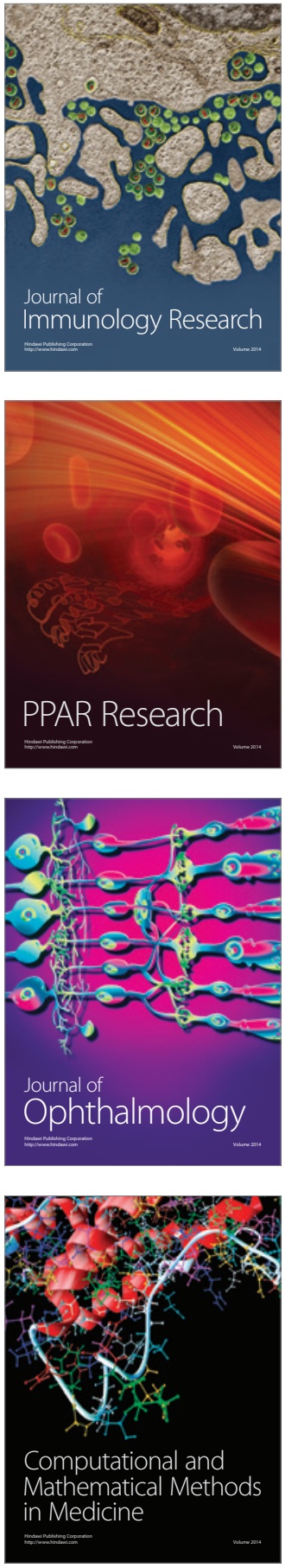

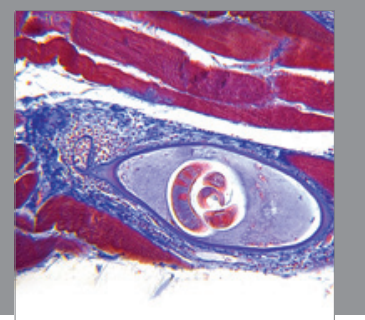

Gastroenterology

Research and Practice
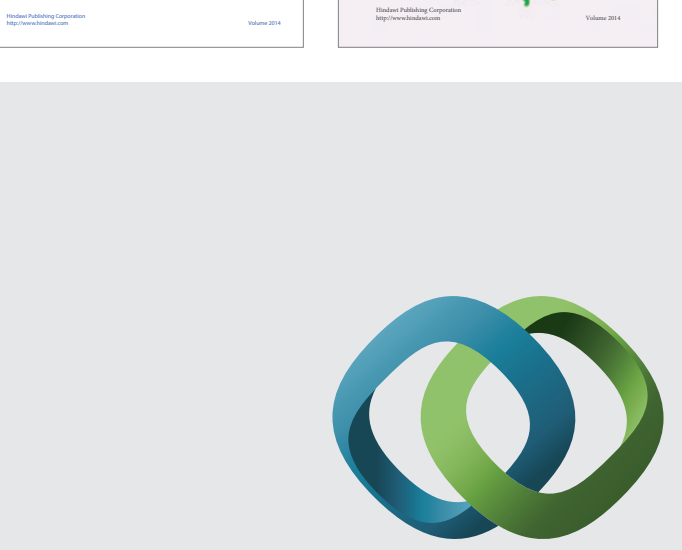

\section{Hindawi}

Submit your manuscripts at

http://www.hindawi.com
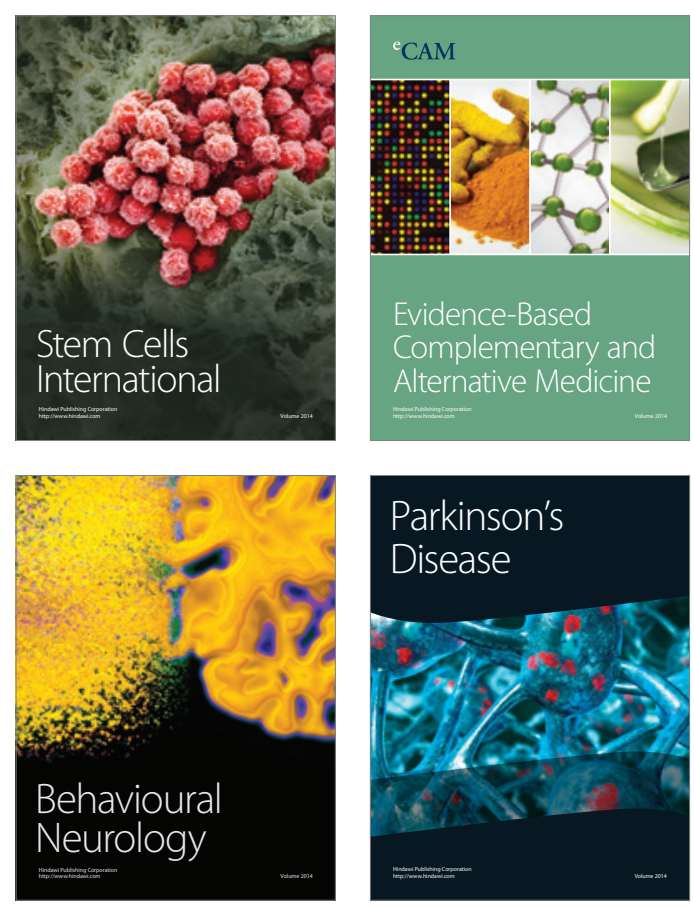

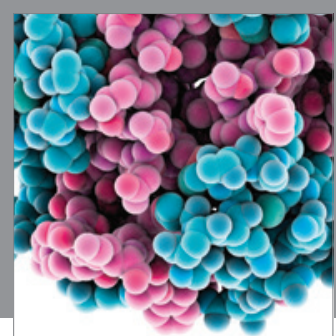

Journal of
Diabetes Research

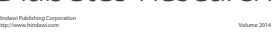

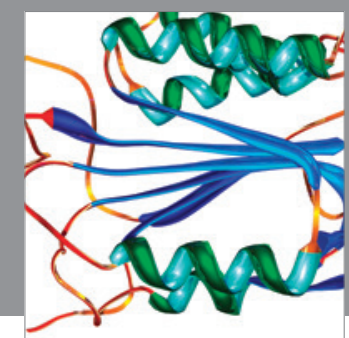

Disease Markers
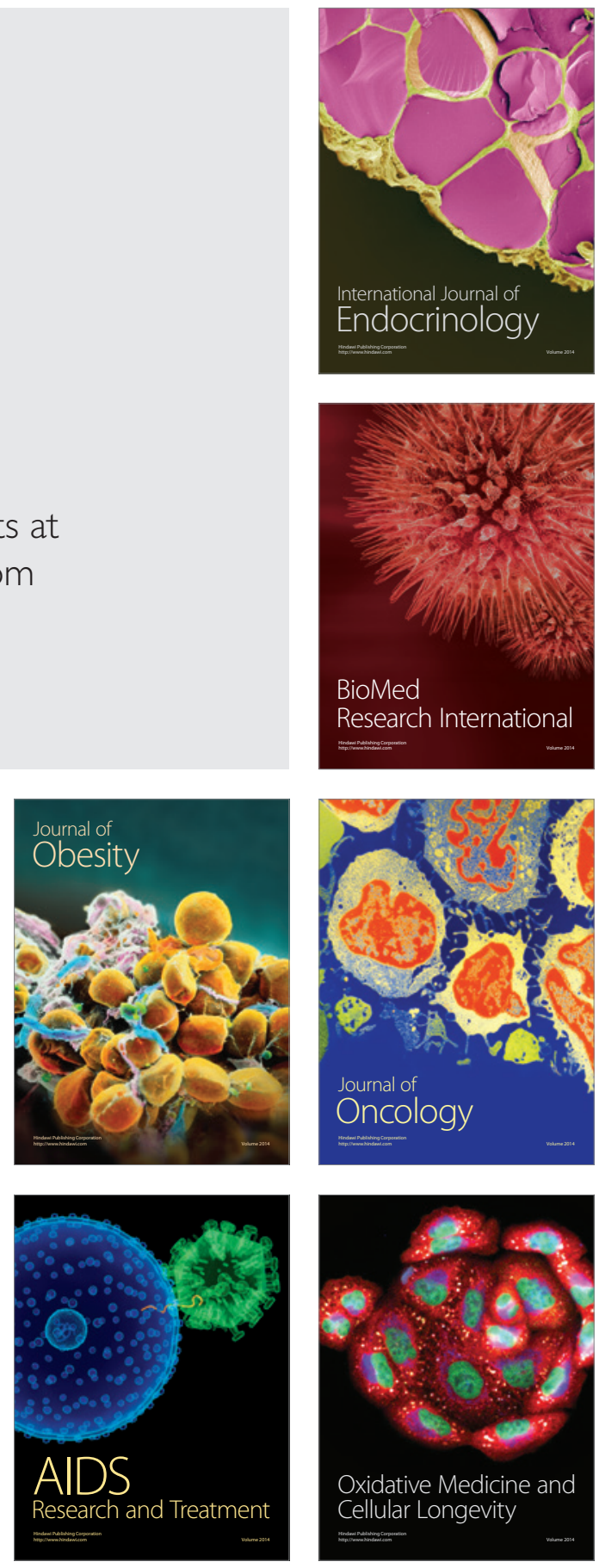